\title{
The incidence of cancer in schizophrenic patients
}

\author{
PREBEN BO MORTENSEN \\ From the Institute of Psychiatric Demography, Aarhus Psychiatric Hospital, DK-8240 Risskov, Denmark.
}

ABSTRACT A cohort of 6168 schizophrenic patients was followed from 1957 to 1984 to determine the incidence of cancer in these patients. In the male schizophrenic patients the incidence of cancer was found to be significantly reduced in comparison with the general Danish population. This reduction was especially marked for cancer in the respiratory system, cancer of the prostate and cancer of the bladder. In the female patients the overall incidence of cancer did not differ from that of the general Danish population, but there was an increased risk of cancer of the digestive tract, especially cancer of the pancreas and a slight increase of the risk of breast cancer. In the female patients the risk of respiratory cancers and cancer of the female genital organs, especially cancer of the uterine cervix, was reduced.

These alterations of the incidence of cancer in schizophrenic patients cannot be ascribed to differences in diagnostic accuracy. As a possible explanation of these findings a reduced exposure to well known carcinogens such as cigarette smoke may be relevant. We speculate that exposure to neuroleptics such as phenothiazines and reserpine may also be part of the explanation for the findings.

The relationship between schizophrenia and cancer has been a subject of controversy among psychiatrists throughout most of this century. This controversy has been sustained by the lack of conclusive empirical evidence with respect to the occurrence of cancer in schizophrenic patients. ${ }^{12}$

It would be of much interest to demonstrate an altered occurrence of cancer in these patients, who are and have been subject to many special living conditions that might have modified the cancer risk. In this way schizophrenic patients form a subpopulation that offers the opportunity to study special risk factors, such as psychotropic drugs.

Most previous studies have been mortality studies, and a few of these have been based on study populations large enough to yield valid estimates of the mortality from cancer in schizophrenics. ${ }^{3-6}$ Cancer mortality, however, is a mixed indicator of cancer occurrence that includes both the susceptibility of developing cancer and the ability to survive the disease. As the latter feature is heavily dependent on medical interventions, a more suitable measurement of cancer occurrence would be the incidence of cancer. The study of the incidence of one uncommon group of diseases, such as cancer, in a group of patients with another rare condition, such as schizophrenia, is, however, associated with many difficulties, because a large group of patients has to be followed for a long time to yield valid estimates of the incidence of cancer.
As a consequence of these difficulties it was decided in 1977 to start an international multicentre study of the incidence of cancer in schizophrenics, under the auspicies of the Division of Mental Health, WHO, Geneva. It has so far only been possible to complete these studies in Japan and Denmark, ${ }^{78}$ though preliminary results have been reported from the Oxford Centre in England. 9

The present study represents an extended follow up of the original Danish study population.

\section{Methods}

The study population consists of all persons who were inpatients in a Danish psychiatric hospital on a census day in 1957 with the diagnosis of schizophrenia. ${ }^{10}$ Of the original 6178 patients, it was possible to re-identify all but 10 . This was made possible by the many registers that are available in Denmark. ${ }^{11}$

A further eight persons had to be excluded, because they had developed cancer before the start of the observation period. Eight persons were excluded for computational reasons since they reached the age of 100 years at some time during the observation period. The final study population thus consisted of 6152 persons, 2956 males and 3196 females. By linkage of the names and the unique identification number of these persons to the Danish Cancer 
Registry, using the methodology described by Jensen, ${ }^{12}$ all patients who had received a cancer diagnosis during the period 26 September 1957 to 31 December 1984 were identified.

The cancer incidence was calculated by using the person-years method. The calculations were performed using the computer programme OVLP 6 developed by Juul. ${ }^{13}$ This programme calculates the incidence rate ratio (IRR), ie, the observed number of cancer cases in the study population divided by the expected number of cases. The expected number of cases was calculated on the basis of the cancer incidence rate in the general Danish population, standardised for age. The calculations were performed separately for each of the periods 1957-62, 1963-67, 1968-72, 1973-77 and 1978-84, using as an external reference the Danish cancer incidence rates that have been published by the Danish Cancer Registry. ${ }^{14-17}$ (The rates from 1981 were used as reference for the period 1978-84). The calculation was performed separately for males and females.

The Danish Cancer Registry has been in existence since 1943 and contains approximately $95-99 \%$ of all diagnosed cancer cases in Denmark. ${ }^{19}$

\section{Results}

The number of cancer cases among schizophrenic patients and the IRR for the 13 main groups of tumours listed in the Danish Cancer Registry are shown in table 1 . The male schizophrenic patients had a significantly reduced incidence of cancer (IRR =0.76). This incidence reduction was especially marked for cancer in the respiratory system, in the male genital organs and in the urinary system. For the group "other and unspecified sites", which in this population mainly consisted of sarcoma with no specified location, there was an increased risk.

In the female schizophrenic patients the overall cancer incidence rate did not differ from that in the general Danish population. There was, however, a slight increase in the incidence rate of tumours of the digestive tract, of metastases, and, as was the case in the males, of tumours in the group "other and unspecified sites". The incidence of respiratory cancers and tumours in the female genital organs was significantly reduced. There was a slight but nonsignificant increase in the risk of developing breast cancer.

In the total population of males and females the overall incidence rate of cancer was significantly reduced (IRR $=0 \cdot 90)$. Most of this risk reduction can be ascribed to the reduced risk of developing respiratory cancers. The risk of developing breast cancer was slightly but significantly increased. The risk of developing tumours in the group "other and unspecified sites" was increased.

The material was further analysed by dividing the cases of cancer into subtypes. The result of this analysis is seen in table 2. Many of the incidence rates differed considerably from those in the general Danisho population. However, these results should be interpreted with great caution because of the smallb numbers in each subgroup. In the male patients cancer of the larynx, lung, prostate, and bladder occurrece with a reduced incidence. No subtype occurred with a significantly increased incidence in the male patients There was, however, a slight non-significant increase in the incidence of cancer of the stomach and oesophagus, and of melanoma.

In the female patients cancer of the pancreas and non-Hodgkin lymphoma occurred with an increased

Table 1 Cancer incidence in 6152 schizophrenic patients 1957-1984; main groups.

\begin{tabular}{|c|c|c|c|c|c|c|}
\hline \multirow[b]{2}{*}{ Tumour site } & \multicolumn{2}{|l|}{ Males } & \multicolumn{2}{|c|}{ Females } & \multicolumn{2}{|c|}{ Males + females } \\
\hline & $\begin{array}{l}\text { No of } \\
\text { cases }\end{array}$ & $I R R^{a}$ & $\begin{array}{l}\text { No of } \\
\text { cases }\end{array}$ & $I R R$ & $\begin{array}{l}\text { No of } \\
\text { cases }\end{array}$ & IRR \\
\hline All sites & 443 & $0.76 \ddagger$ & 585 & 1.06 & 1028 & 0.907 \\
\hline Buccal cavity & 11 & 0.65 & 4 & 0.55 & 15 & 0.62 \\
\hline Digestive tract & 174 & 0.93 & 210 & $1 \cdot 16^{*}$ & 384 & 1.05 \\
\hline Respiratory system & 42 & $0.35 \ddagger$ & 15 & $0.53 t$ & 57 & $0.38 \ddagger$ \\
\hline Breast & 2 & 1.85 & 125 & $1 \cdot 19$ & 127 & $1 \cdot 19^{*}$ \\
\hline Female genital organs & - & - & 70 & $0.74 \uparrow$ & - & - \\
\hline Male genital organs & 44 & $0.57 \ddagger$ & - & - & - & - \\
\hline Urinary system & 47 & $0.72^{*}$ & 38 & $1 \cdot 26$ & 85 & 0.89 \\
\hline Skin & 63 & 0.91 & 52 & 0.90 & 115 & 0.90 \\
\hline Other specified sites & 14 & 0.83 & 19 & 1.05 & 33 & 0.95 \\
\hline Metastases & 8 & 0.94 & 16 & $1.65^{*}$ & 24 & $1 \cdot 32$ \\
\hline Other and unspecified sites & 12 & $2.59 t$ & 25 & $2 \cdot 48 \pm$ & 37 & $2 \cdot 52 \ddagger$ \\
\hline Lymphatic and haematopoietic system & 32 & 0.88 & 28 & 0.96 & 60 & 0.92 \\
\hline
\end{tabular}

a IRR = observed/expected no of cases standarised for sex and age.

* $\mathrm{p}<0.05 ;$ †p $<0.01 ;$ †p $<0.001$ 
Table 2 Cancer incidence in 6152 schizophrenic patients 1957-1984; subtypes.

\begin{tabular}{|c|c|c|c|c|c|c|}
\hline \multirow[b]{2}{*}{ Tumour site } & \multicolumn{2}{|l|}{ Males } & \multicolumn{2}{|c|}{ Females } & \multicolumn{2}{|c|}{ Males + females } \\
\hline & $\begin{array}{l}\text { No of } \\
\text { cases }\end{array}$ & IRR & $\begin{array}{l}\text { No of } \\
\text { cases }\end{array}$ & $I R R$ & $\begin{array}{l}\text { No of } \\
\text { cases }\end{array}$ & $I R R$ \\
\hline Lip & 6 & 0.66 & 1 & 0.88 & 7 & 0.68 \\
\hline Oesophagus & 9 & $1 \cdot 18$ & 6 & $1 \cdot 21$ & 15 & 1.19 \\
\hline Stomach & 63 & $1 \cdot 20$ & 52 & $1 \cdot 26$ & 115 & $1 \cdot 26^{*}$ \\
\hline Colon + rectum & 71 & 0.81 & 99 & 1.07 & 170 & 0.94 \\
\hline Liver & 7 & 0.82 & 8 & $1 \cdot 11$ & 15 & 0.95 \\
\hline Biliary tract & 9 & 1.60 & 17 & $1 \cdot 32$ & 26 & 1.41 \\
\hline Pancreas & 14 & 0.64 & 32 & $1.59 t$ & 46 & $1 \cdot 10$ \\
\hline Larynx & 2 & $0.25^{*}$ & 2 & 1.76 & 4 & 0.43 \\
\hline Lung & 36 & $0.34 t$ & 7 & $0.29 t$ & 43 & $0.33 \pm$ \\
\hline Lung, not primary & 2 & 0.90 & 3 & $3 \cdot 30^{*}$ & 5 & 1.60 \\
\hline Uterine cervix & - & - & 20 & 0.68 & - & - \\
\hline Uterine corpus & - & - & 22 & 0.78 & - & - \\
\hline Ovary & - & - & 23 & 0.78 & - & - \\
\hline Prostate & 40 & $0.56 t$ & - & - & - & - \\
\hline Testis & 1 & 0.39 & - & - & - & - \\
\hline Kidney & 16 & 0.87 & 21 & 1.46 & 37 & $1 \cdot 13$ \\
\hline Bladder & 31 & $0.66^{*}$ & 17 & 1.08 & 48 & 0.78 \\
\hline Melanoma & 6 & $1 \cdot 17$ & 8 & $1 \cdot 12$ & 14 & $1 \cdot 14$ \\
\hline Brain & 7 & 0.69 & 15 & 1.50 & 22 & 1.45 \\
\hline Non-Hodgkin lymphoma & 8 & 0.83 & 15 & $1 \cdot 70^{*}$ & 23 & $1 \cdot 24$ \\
\hline Hodgkin's lymphoma & 1 & 0.35 & 2 & 1.03 & 3 & 0.63 \\
\hline Malignant myeloma & 7 & 1.01 & 4 & 0.67 & 11 & 0.85 \\
\hline Leukaemia & 17 & 1.02 & 8 & 0.65 & 25 & 0.87 \\
\hline
\end{tabular}

p $<0.05 ;$ †p $<0.01 ;$ tp $<0.001$

incidence. The incidence of lung cancer was significantly lowered.

When looking at the total population, cancer of the stomach occurred with an increased incidence and cancer of the lung occurred with a decreased incidence.

\section{Discussion}

The finding of a reduced incidence of certain types of cancer in a special population such as schizophrenic patients immediately raises the question as to whether differences in diagnostic practices may account for the findings. This explanation finds support in the fact that several reports have been made of the frequent occurrence of unrecognised medical illnesses in psychiatric patients. ${ }^{20-24}$ If this was the explanation of the findings in this study population, one would expect cancer to have been diagnosed by the unexpected finding of a tumour at autopsy to a greater extent than in the general Danish population. However, an investigation of 108 hospital records of schizophrenic cancer patients from this patient population showed that only one of these patients had had cancer diagnosed at autopsy. The autopsy rate in the schizophrenic patients $(\mathbf{4 6 . 9 \% )}$ did not differ significantly from that of the general Danish population $(42.7 \%)$. Therefore it seems justified to believe that the procedure for diagnosing cancer in these schizophrenic patients has been at least as efficient as in the general Danish population, and it must be concluded that the findings in this study represent real differences in cancer incidence rates. ${ }^{25}$

Of other possible explanations of these findings, an altered exposure to well known carcinogens must be considered. As the reduced incidence of cancer in these patients can be attributed especially to a reduced incidence of respiratory cancers, tobacco smoking in particular must be considered. It is well known that schizophrenic patients today are very heavy smokers. ${ }^{26}$ However, the smoking habits that are relevant for the cancer incidence in this study population are those of the 50s and 60s. During this period smoking in this study population of schizophrenic patients was very limited, partly because of the limited amount of money these patients had at their disposal, and partly because of prohibition against smoking in Danish psychiatric hospitals. The money available for schizophrenic patients in this period would cover only about one pack of cigarettes a week at a maximum. Therefore, it seems justified to believe that the limitation of cigarette smoking in the 50 s and early 60 s has contributed to the lowered incidence of cancer that has now been found.

As regards the slight reduction in cancer of the uterine cervix, this may be explained by reduced sexual activity in the female schizophrenic patients. ${ }^{27}$ Sexual activity is lowered partly because of the patients' mental disorder, and partly because of an often life long placement in a closed female ward in a psychiatric hospital. The low rate of pregnancies may also partly explain the increased risk of developing breast cancer. $^{28}$

A point of considerable interest is whether 
treatment with neuroleptics has modified the cancer incidence in these patients. A pilot study has been performed and published ${ }^{29}$ in which male schizophrenic patients with cancer of the lung or cancer of the bladder and female schizophrenic patients with cancer of the breast or cancer of the uerine cervix were compared to age and sex matched controls from the same cohort of schizophrenic patients, using a logistic regression model. These were also compared with respect to exposure to risk factors such as occupation, duration of admission to a psychiatric hospital, and parity as to the various types of neuroleptics, including reserpine which found widespread use as a neuroleptic drug in schizophrenic patients in the period from 1954 to the mid 60s. It later lost its popularity as a neuroleptic because of its tendency to induce depression. Reserpine has been reported to increase the risk of developing cancer of the breast, ${ }^{30-32}$ but other studies have not confirmed these findings. ${ }^{33-35}$ In this population, however, where reserpine had often been given in dosages much higher than those generally used in the treatment of hypertension, its use was associated with a clear and significant increase in the risk of developing not only breast cancer, but also cancer of the uterine cervix. .

As a possible mechanism for the breast cancer inducing effect of reserpine, it has been suggested that it could be mediated through the ability of this agent to elevate serum prolactin levels. ${ }^{36}$ However, other neuroleptics, for example the phenothiazines, also elevate serum prolactin levels without increasing the risk of breast cancer. ${ }^{37} 39$ It thus seems that the cancer inducing effect of reserpine must be mediated through other mechanisms.

Reserpine was used more frequently in the female than in the male patients. This may be the explanation for the differences in the incidence of cancer of the pancreas between the male and the female patients, as a (non-significantly) increased risk of cancer of the pancreas has been described in association with reserpine use. ${ }^{30}$

Other neuroleptics such as the phenothiazines have been reported to inhibit tumour growth in animal experimental models. ${ }^{38} 39$ In the Danish investigation ${ }^{29}$ in this patient population neuroleptics other than reserpine were found to reduce the incidence of cancer of the lung, bladder, uterine cervix and breast. It thus seems that medication with psychotropic drugs may in part explain the differences in cancer incidence in this population of schizophrenic patients compared with the general Danish population. There is no obvious explanation for the increased incidence of cancer of the stomach. One possible explanation may be found in the fact that these patients generally come from a poor social background, and an increased risk of cancer of the stomach associated with low social class has been reported. ${ }^{40}$

There is no obvious explanation for the reduced risk of cancer of the prostate or the increased risk of non-Hodgkin lymphoma in the female patients. A case-control study of the relation between cancer of the prostate and the use of neuroleptics is now being carried out by the author.

It can be concluded that the differences in cancer incidence found between schizophrenic patients and the general Danish population may be explained partly by reduced exposure to well known carcinogens such as tobacco smoking, and partly by the cancer reducing effect of some neuroleptic drugs and the risk increasing effect of reserpine. Therefore further studies to clarify the possible role of drugs, such as the phenothiazines, in the prophylaxis and treatment of cancer seem to be indicated.

The author wishes to thank Dr A Dupont, Dr Povl Munk-Jørgensen, secretaries Anne Tjørnemose and Mona Bendtsen and programmer Søren Skadhede for their help and advice during the course of the study.0 The original re-identification of the study population was performed by $\mathrm{Dr} A$ Dupont, Professor $\mathrm{E} \Omega$ Strömgren and secretary Mona Bendtsen. Furthero material for this study was provided by the Danish Cancer Registry.

The study was supported by Sygekassernes Helsefond (grant no H11/25-87) and Fonden til Psykiatriens Fremme.

\section{References}

${ }^{1}$ Baldwin JA, Schizophrenia and physical disease. Psychol Med 1979; 9: 611-8.

2 du Pan RM, Müller C. La mortalité par cancer chez les patients psychiatriques hospitalisées. Schweiz Med Wochenschr 1977; 107: 597-604.

${ }^{3}$ Katz J, Kunofsky S, Patton RE, Allaway NC. Cancer mortality among patients in New York Mental Hospitals. Cancer 1967; 20: 2194-9.

4 Ciompi L, Müller C. Lebensweg und Alter der Schizophrenen, Eine katamnestische Langzeitstudie bis ins Senium. Berlin, Heidelberg, New York: Springer-Verlag, 1976.

5 Saugstad LF, Ødegaard $\varnothing$. Mortality in psychiatric hospitals in Norway 1950-74. Acta Psychiatr Scand 1979; 59: $431-47$.

6 Alström CH. Mortality in mental hospitals. With especial regard to tuberculosis. Copenhagen: Munksgaard, 1942.

7 Dupont A, Jensen OM, Strömgren E, Jablensky A. Incidence of cancer in patients diagnosed as schizophrenic in Denmark. In: ten Horn GHMM, Giel R, Gulbinat WH, Henderson JH, eds. Psychiatric case registers in public health. A worldwide inventory 1960 1985. Amsterdam, New York, Oxford: Elsevier, 1986: 229-39. 
${ }^{8}$ Nakane Y, Ohta Y. The example of linkage with a cancer register. In: ten Horn GHMM, Giel R, Gulbinat WH, Henderson $\mathrm{JH}$, eds. Psychiatric case registers in public health. A worldwide inventory 1960-1985. Amsterdam, New York, Oxford: Elsevier, 1986: 240-5.

${ }^{9}$ Herrman HE, Baldwin JA, Christie D. A record-linkage study of mortality and general hospital discharge in patients diagnosed as schizophrenic. Psychol Med 1983; 13: 581-93.

${ }^{10}$ Arentsen K, Strömgren E. Patients in Danish psychiatric hospitals. Acta Jutlandica 1959; 31, Medicinsk serie 9.

11 Andersen TF. Genanvendelse af historiske datamaterialer. Ugeskr Laeger 1980; 142: 1054-8.

12 Jensen OM. Cancer morbidity and causes of death among Danish brewery workers. Lyon: World Health Organization, International Agency for Research on Cancer, 1980.

13 Juul S. Programmer til overlevelsesberegninger. Aarhus: Socialmedicinsk Institut, Aarhus Universitet, rapp. no 1, 1984.

${ }^{14}$ Clemmesen J. Statistical studies in the aetiology of malignant neoplasms. III. Testis cancer, Basic tables, Denmark 1958-62. Copenhagen: Munksgaard, 1969.

15 Clemmesen J. Statistical studies in malignant neoplasms. IV. Lung/bladder ratio. Denmark 1943-67. Copenhagen: Munksgaard, 1974.

${ }^{16}$ Clemmesen J. Statistical studies in malignant neoplasms. $V$. Trends and risks. Denmark 1943-72. Copenhagen: Munksgaard, 1977.

${ }^{17}$ Danish Cancer Registry. Incidence of cancer in Denmark 1973-1977. Copenhagen: Danish Cancer Registry, 1982.

${ }^{18}$ Danish Cancer Registry. Cancer incidence in Denmark 1981 and 1982. Copenhagen: Danish Cancer Registry, 1985.

${ }^{19}$ Osterlind A, Jensen OM. Evaluering af cancerregistreringen i Danmark. En præliminær evaluering af cancerregistrering og landspatientregisterets registrering af cancertilfælde. Ugeskr Laeger 1985; 147: 2483-8.

${ }^{20}$ Herridge CF, Cantab MB. Physical disorders in psychiatric illness. A study of 209 consecutive admissions. Lancet 1960; ii: 949-51.

21 Johnson DAW. The evaluation of routine physical examination in psychiatric cases. Practitioner 1968; 200: 686-91.

${ }^{22}$ Hall RCW, Popkin MK, Devaul RA, Faillace LA, Stickney SK. Physical illness presenting as psychiatric disease. Arch Gen Psychiatry 1978; 35: 1315-20.

${ }^{23}$ Hall RCW, Gardner ER, Popkin MK, Lecann AF, Stickney SK. Unrecognized physical illness prompting psychiatric admission: A prospective study. Am J Psychiatry 1981; 138: 629-35.
${ }^{24}$ Hall RCW, Beresford TP, Gardner ER, Popkin MK. The medical care of psychiatric patients. Hosp Community Psychiatry 1982; 23: 25-34.

25 Mortensen PB. Cancerdiagnostik og autopsifrekvens blandt skizofrene patienter. Ugeskr Laeger 1987; 149: 1973-5.

${ }^{26}$ Masterson E, O'Shea B. Smoking and malignancy in schizophrenia. Br J Psychiatry 1984; 145: 429-32.

${ }^{27}$ Rotkin ID. Comparison review of key epidemiological studies in cervical cancer related to current searchers for transmissible agents. Cancer Res 1973; 33: 1353-67.

${ }^{28}$ Miller AB. The epidemiology of breast cancer. In: Ames FC, Blumenschein GR, Montague ED, eds. Current controversies in breast cancer. Austin, Texas: University of Texas, 1984: 25-36.

${ }^{29}$ Mortensen PB. Neuroleptic treatment and other factors modifying cancer risk in schizophrenic patients. Acta Psychiatr Scand 1987; 75: 585-90.

${ }^{30}$ Boston Collaborative Drug Surveillance Program. Reserpine and breast cancer. Lancet 1974; ii: 669-71.

31 Armstrong B, Stevens N, Doll R. Retrospective study of the association between use of rauwolfia derivtives and breast cancer in English women. Lancet 1974; ii: 672-5.

32 Heinonen OP, Shapiro S, Tuominen L, Turunen MI. Reserpine use in relation to breast cancer. Lancet 1974; ii: 675-7.

${ }^{33}$ Laska EM, Siegel C, Meisner M, Fischer S, Wanderling J. Matched-pairs study of reserpine use and breast cancer. Lancet 1975; ii: 296-300.

34 Mack TM, Henderson BE, Gerkins VR et al. Reserpine and breast cancer in a retirement community. $N$ Engl $J$ Med 1975; 292: 1366-71.

35 O'Fallon WM, Laberthe DR, Kurland LR. Rauwolfia derivatives and breast cancer. Lancet 1975; ii: 292-6.

36 Schyve PM, Smithline F, Meltzer HY. Neurolepticinduced prolactin level elevation and breast cancer. An emerging clinical issue. Arch Gen Psychiatry 1978; 35: 1291-1301.

${ }^{37}$ Kanhouwa S, Gowdy JH, Solomon JD. Phenothiazines and breast cancer. J Natl Med Assoc 1984; 76: 785-88.

38 Pamukcu AM, Wattenberg LW, Price JM, Bryan GT. Phenothiazine inhibition of intestinal and urinary bladder tumours induced in rats by bracken fern. $J$ Natl Cancer Inst 1971; 47: 155-9.

${ }^{39}$ Driscoll JS, Melnick NR, Quinn FR et al. Psychotropic drugs as potential antitumor agents: A selective screening study. Cancer Treat Rep 1978; 62: 45-74.

40 Clemmesen J. Statistical studies in the aetiology of malignant neoplasms. I. Review and results. Copenhagen: Munksgaard, 1965.

Accepted for publication October 1988 